\title{
A CONTAÇÃO DE HISTÓRIA COMO RECURSO PARA A FORMAÇÃO DE LEITORES: PRÁTICAS LEITORAS PARA OS ANOS INICIAIS DO ENSINO FUNDAMENTAL
}

\author{
HISTORY TELLING AS A RESOURCE FOR TRAINING READERS: READING PRACTICES FOR \\ THE EARLY YEARS OF ELEMENTARY EDUCATION
}

\section{LA HISTORIA COMO RECURSO PARA LA FORMACIÓN DE LECTORES: PRÁCTICAS DE LECTURA PARA LOS PRIMEROS AÑOS DE LA EDUCACIÓN PRIMARIA}

\author{
Neide Figueiredo de Souza1 \\ Luana Teixeira Porto 2
}

\section{RESUMO}

Este artigo aborda a contação de história como recurso pedagógico para a formação de leitores. Questiona-se: De que forma a contação de histórias pode contribuir para a formação leitora nos anos iniciais do Ensino Fundamental? Que práticas leitoras podem ser propostas para estimular a leitura nesse nível de ensino? Partindo-se do pressuposto de que a leitura é essencial às práticas escolares e que é preciso estimular a compreensão de textos como forma de ampliação de visão de mundo, busca-se, como objetivo geral, refletir sobre a contação de histórias como estratégia para o estímulo da leitura nos anos iniciais do Ensino Fundamental. Para desenvolver o estudo, como fundamento teórico, foram explorados trabalhos e proposições teórico-críticas e orientações da Base Nacional Curricular Comum sobre a leitura e a formação de leitores, a contação de histórias e a formação leitora. Considerando estudos de autores diversos, construiu-se uma sequência de proposições didáticas que embasam a contação de histórias para a formação de leitores nos anos iniciais do ensino fundamental. As propostas abordaram diferentes temas, tendo como fio condutor as noções de identidade e diferença, consideradas essenciais para a formação humana.

PALAVRAS-CHAVES: contação de histórias; formação leitora; ensino fundamental; sequência didática.

\begin{abstract}
This article approaches storytelling as a pedagogical resource for the formation of readers. The question is: In what way can storytelling contribute to reading training in the early years of elementary school? What reading practices can be proposed to stimulate reading at this level of education? Based on the assumption that reading is essential to school practices and that it is necessary to encourage the comprehension of texts as a way of expanding the worldview, the general objective is to reflect on storytelling as a strategy for the encouragement of reading in the early years of elementary school. To develop the study, as a theoretical foundation, works and theoretical-critical propositions and guidelines of the Common National Curriculum Base on reading and reader training, storytelling and reader training were explored. Considering studies by different authors, a sequence of didactic propositions that support storytelling for the formation of readers in the early years of elementary school was built. The proposals addressed different themes, having as a guiding principle the notions of identity and difference, considered essential for human formation.
\end{abstract}

KEYWORDS: storytelling; reader training; elementary School; following teaching.

\section{RESUMEN}

Este artículo aborda el storytelling como un recurso pedagógico para la formación de lectores. La pregunta es: ¿De qué manera la narración puede contribuir a la formación en lectura en los primeros años de la escuela primaria? ¿Qué prácticas lectoras se pueden proponer para estimular la lectura en este nivel educativo?

\footnotetext{
${ }^{1}$ Mestra em Educação. Email: neidefigueiredo55@hotmail.com

2 Doutora em Letras. Email: Iuanatporto@gmail.com

Revista de Ciências Humanas, Frederico Westphalen - RS, v. 22, n.2, p. 03-26, maio/ago. 2021.

Recebido em: 03/05/2021 $\quad$ Aceito em: 27/06/2021
}


Partiendo del supuesto de que la lectura es fundamental para las prácticas escolares y que es necesario fomentar la comprensión de los textos como forma de ampliar la cosmovisión, el objetivo general es reflexionar sobre el storytelling como estrategia para el fomento de la lectura en los primeros años. de la escuela primaria. Para desarrollar el estudio, como fundamento teórico, se exploraron trabajos y proposiciones teórico-críticas y lineamientos de la Base Curricular Nacional Común sobre lectura y formación de lectores, narración y formación de lectores. Considerando estudios de diferentes autores, se construyó una secuencia de propuestas didácticas que apoyan la narración para la formación de lectores en los primeros años de la escuela primaria. Las propuestas abordaron diferentes temas, teniendo como principio rector las nociones de identidad y diferencia, consideradas fundamentales para la formación humana.

PALABRAS CLAVE: narración; formación de lectores; enseñanza fundamental; siguiendo la enseñanza.

\section{CONSIDERAÇÕES INICIAIS}

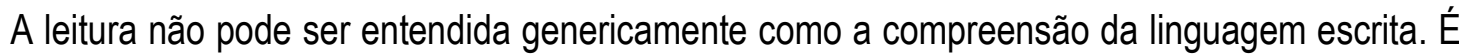
mais do que decifração da palavra. É, segundo os Parâmetros Curriculares Nacionais (BRASIL, 1998, p. 41), "um processo no qual o leitor realiza um trabalho ativo de construção do significado do texto, a partir de seus objetivos, do seu conhecimento sobre o assunto [...]". Portanto, é um processo adquirido pelo sujeito em longo prazo, e, nesse processo, a ação docente desde os primeiros contatos da criança com a escola poderá auxiliar na obtenção de hábito e gosto pela leitura ou poderá afastar o aluno dos livros se não houver uma ação pedagógica permanente e eficiente para despertar no infante o prazer em ler. Nessa perspectiva, o principal objetivo do professor deverá ser a formação do bom leitor embora essa não seja uma tarefa exclusiva do docente.

Longe de ser um clichê, também é papel da família a promoção da leitura em casa e o estímulo para ler, pois deve contribuir para a formação da criança no que se refere às questões, entre outros elementos, do exercício da cidadania e da comunicação, assim como da significação do que infante vê, ouve, lê. Por isso, é importante que a família compreenda a necessidade de sua participação na construção deste hábito indispensável, que é o hábito de ler em casa e desenvolver na criança o contato com leituras em diferentes gêneros, suportes e linguagens.

Para tanto, o primeiro passo da família é fazer-se um exemplo para a criança, de modo que ela se sinta estimulada a ler ao ver as pessoas de seu convívio praticando a leitura de forma prazerosa. Os pais ou responsáveis devem servir de inspiração à criança ao hábito de ler. Já nas atividades de práticas leitoras na escola, além da observação também necessária sobre o tema dos textos, é preciso outro cuidado, pois sabemos que a leitura nem sempre deve ser ofertada para essa aproximação do texto com a vida real. Pode ser meio para abordagem de temas que interessam ao universo do leitor dada a sua faixa etária e desenvolvimento emotivo, cognitivo, social. Nessa linha de raciocínio, segundo os Parâmetros Curriculares do Ensino Fundamental (BRASIL, 1997, p. 41), a leitura é uma prática social e, "Para que possa constituir também objeto de aprendizagem, é necessário que faça 
sentido para o aluno, isto é, a atividade de leitura deve responder, do seu ponto de vista, a objetivos de realização imediata.".

A leitura implica, portanto, várias habilidades: reconhecimento de linguagens, intencionalidades, estruturas dos textos... E tudo isso leva ao letramento, conceito chave para as atividades docentes no contexto atual da Educação brasileira. De acordo com Soares (2008), o letramento está intrinsecamente relacionando à compreensão de leitura e escrita como práticas sociais, privilegiando a prática da língua portuguesa no nosso cotidiano. Ainda segundo a autora, "no caso da leitura, os aprendizes, [...] precisam, para além da simples codificação/decodificação de símbolos e caracteres, passar por um processo de 'compreensão/expressão de significados do código escrito'." (2008, p. 16).

Ao ser aberta a porta do conhecimento por meio da leitura, presumimos que aconteça a interação da criança com o contexto de leitura. Acerca desse pensamento, Solé (2014, p. 22) afirma que "[...] a leitura é um processo de interação entre o leitor e o texto; neste processo tenta-se satisfazer [obter uma informação pertinente para] os objetivos que guiam sua leitura.". A mesma pesquisadora afirma que um dos maiores desafios da escola é fazer com que os alunos leiam proficientemente. Isso, pois, é formar o aluno leitor e significa capacitá-lo para agir com autonomia nas sociedades letradas (ser alfabetizado é insuficiente hoje).

Diante dessa afirmação, compreendemos que não basta a leitura sem a compreensão da "mensagem" que o texto quer registrar. Não basta "soletrar" ou "juntar as palavras" sem saber o significado delas no texto, sem entender o contexto do texto. Apenas com decodificação, a leitura torna-se automática, sem sentido, incompleta e até mesmo desmotivadora. E não esse o movimento adequado e exitoso para o processo de formação de leitor.

Mesmo que tenhamos noção sobre o que deve ser demonstrado enquanto habilidade leitora, há diversos problemas associados ao ensino e à prática de leitura na escola. Segundo Solé (2014), o problema do ensino da leitura na escola não se resume somente ao método, mas também ao próprio conceito do que é leitura, a forma como ela é avaliada e favorecida, as propostas metodológicas utilizadas no seu ensino. A estudiosa compara que o ensino da leitura à construção de uma casa, afirmando que esta não pode começar pelo telhado, ou seja, nem sempre o fim (aprender a ler bem) justifica os meios (pedagógicos de abordagem da leitura na sala de aula).

Outrossim, nem sempre 0 método utilizado para 0 ensino da leitura favorece sua aprendizagem. $O$ aluno não pode pensar na leitura como uma atividade obrigatória, ainda que o seja. Existem, sim, desafios nesse processo, devendo o educador atentar-se aos primordiais, como oferecer à criança subsídios que the permitam vivenciar situações que estimulem o hábito da leitura - associar a 
leitura ao cotidiano da criança. E um desses subsídios pode ser a contação de histórias como uma prática leitora para despertar o gosto pela leitura literária e pelos livros. Exatamente por observar 0 quanto as crianças se envolvem numa história ao ouvi-la e por compreender que é preciso pensar em práticas leitoras adequadas a alunos que estão nos anos iniciais do Ensino Fundamental é que optamos por abordar o tema. Dessa forma, o tema desta pesquisa é "A contação de história como recurso para a formação de leitores: proposição de práticas leitoras para os anos iniciais do Ensino Fundamental." Entendemos que as práticas leitura referem-se à:

(i) criação de situações reais de leitura em sala de aula, bem como à (ii) busca de apreensão e negociação dos significados que os aprendizes atribuem à leitura em geral, bem como à leitura de diferentes gêneros. Em se tratando da criação de situações reais de leitura, a noção pedagógica de práticas de leitura retoma, ainda que de forma ampliada, a de "usos sociais da língua escrita" ou de "usos sociais da leitura". Ela busca recriar, no interior da escola, as práticas de leitura que ocorrem em outras esferas do mundo social e não apenas fazer atividades para aprender a ler. (BATISTA, 2019, p. 01).

Não se trata de esgotarmos todas as referências que abordam a temática, mas, sim, de apresentarmos um aprofundamento sobre a formação leitora que nos permita discutir a contribuição da estratégia da contação de histórias na formação leitora de estudantes nos primeiros anos do Ensino Fundamental. Reconhecemos que a aprendizagem da leitura de ser estimulada e motivada, respeitando o tempo de aprendizagem do aluno, de modo que cada estratégia a ser utilizada nesse processo seja muito bem planejada, levando-o ao pleno desempenho da leitura (compreender o que lê e ser capaz de reproduzir o que leu).

Diante do exposto, este artigo aborda relações entre contação de histórias e formação leitora, com foco na proposição de práticas leitoras com vistas ao desenvolvimento do gosto e do hábito de leitura anos iniciais do Ensino Fundamental. O objetivo é refletir sobre a contação de histórias como estratégia para o estímulo da leitura nos anos iniciais do Ensino Fundamental.

\section{A LEITURA NOS ANOS INICIAIS DO ENSINO FUNDAMENTAL}

Para Bamberger (2000), desenvolve-se o interesse pela leitura quando este é "alimentado", e, para fazê-lo, somente motivando hábito de ler. Entre os principais fatores para essa ação, este autor refere-se à leitura oral, a qual deve ser sempre realizada sem interrupções e sem correções, no momento em que o aluno a está fazendo. De modo geral, o aluno se prende ao que está lendo, mantém o ritmo do texto e aprende o significado do que está lendo. Atitudes contrárias a essas podem criar no aluno o medo de ler "errado" e a falta de interesse pela leitura. Além disso, propor leitura de livros e textos diferentes é sempre motivador. 
De acordo com Bamberger (2000, p. 92), "o desenvolvimento de interesses e hábitos permanentes de leitura é um processo constante, que começa no lar, aperfeiçoa-se sistematicamente na escola e continua vida afora." Essa afirmação aponta a leitura como um hábito que vem (ou pelo menos deveria vir) desde antes da inserção da criança na escola, no seio familiar.

Ainda segundo Bamberger (2000), desenvolver a formação leitora, o gosto e o interesse pela leitura estão atrelados ao que cerca o aluno leitor, ou seja, seja no meio onde ele (o aluno) recebe estímulo para ler, e então desenvolverá o hábito de ler. E, para formar leitores bem sucedidos, faz-se necessário propor-Ihes leituras apropriadas, de modo que a cada leitura o leitor absorva o que está lendo e leve isso por toda a sua vida.

Silva (1987) expõe que viveu muitas experiências de trabalho junto aos professores brasileiros, em especial, do Ensino Fundamental. Nessas experiências, observou que existem muitas formas de pensar (conceito) e orientar 0 ato de ler pelos professores nas mais diferentes séries. Diante dessa percepção, questionava aos professores o conceito de leitura e deparou-se com um conjunto de concepções as quais thes serviam como orientações das atividades de leitura.

Em suas indagações aos professores, Silva (1987) confirmou que a maioria concebe o conceito de leitura de forma muito simplista, desprezando os elementos fundamentais da leitura, valendo-se de materiais pobres (livros, textos, ambiente e outros) para a prática de leitura. E o autor, isso conduz ao empobrecimento de pensamento dos próprios professores, que são os responsáveis por planejar e orientar essas práticas, e, num segundo momento, de seus alunos.

Silva (1987) afirma que a concepção simplista dos professores reduz a leitura à ação de oralizar o texto, no sentido de apenas exprimir oralmente as palavras do texto, em apenas verbalizálas. Então, este mesmo autor afirma que:

\begin{abstract}
Ler é ler voz alta, obedecendo as regras de entoação das frases, apresentando boa postura expressiva, formando unidades frasais entre os enunciados orais, obedecendo as pausas de pontuação, etc. Como a atenção docente se volta para a eloquência ou expressividade verbal, os aspectos de compreensão das idéias evocadas pelo texto podem se perder dentro do formalismo do encaminhamento metodológico. Daí o surgimento, na escola, do leitor "papagaio" ou "vitrola", que é sem dúvida capaz de transformar os símbolos escritos em símbolos orais, mas sem nenhuma preparação para compreender as idéias referenciadas pelos textos. [sic] (SILVA, 1987, p. 12-13).
\end{abstract}

Essa fala de Silva remete à certeza de que ler é num primeiro momento, traduzir a escrita em fala. É também decodificar mensagens, levando em conta os componentes do processo de leitura: (autor/emissor, texto/mensagem, leitor/receptor ou destinatário. Muito importante, argumenta Silva (1987), é o professor não levar o aluno à leitura passiva, àquela que não produz sentidos ao que se lê. É preciso o professor planejar a leitura pelo aluno, considerando: os propósitos do que se vai ler, o 
repertório e interesse do alunado por ele, os conhecimentos e sentimentos que se pretende que sejam decodificados.

Outro conceito dado por Silva:

Ler é dar respostas a sinais gráficos. Esta concepção está intimamente relacionada à ossatura teórica das teorias de aprendizagem do associacionismo ou behaviorismo em psicologia. O chamado esquema $S$ (estímulo) - $R$ (resposta), oriundo dos experimentos pavlovianos ${ }^{3}$ com animais em situação de laboratório, ainda encontra vasta consagração no meio escolar [...]. Neste caso, o texto é o estímulo e a leitura, a resposta. Caso o leitor "acerte" a resposta prevista ou pré-determinada pelo professor [...], então esse aluno será "reforçado" - caso ele erre a resposta prevista, será "punido". Despreza-se aqui quaisquer possibilidades de um mesmo texto permitir diferentes interpretações ou sentidos, mesmo porque uma resposta protocolar, firmada pelo professor, é privilegiada no intuito de permitir correção e controle. (SILVA, 1987, p. 12-13).

Essa compreensão do autor remete a admitir que, entre um estímulo e uma resposta pelo que foi lido, há alguém (o professor) que intermedeia essa ação e reação no aluno. Interessa entender que um mesmo texto pode ser interpretado de forma diferente de um aluno para outro e, dependendo do que se trata o texto, não há, por parte do aluno, o certo e o errado. Diante de uma "falsa compreensão", é possível o professor promover uma discussão e acertar com a participação dos alunos a mensagem que de fato o texto quer transmitir.

Para Lajolo e Zilberman (2002), o ato de ler não se resume em decifrar, como se faz, em um jogo de adivinhações, o sentido de um texto. Mas é a partir do texto e de sua reflexão sobre ele que o leitor será capaz de atribuir-Ihe significado, conseguir relacioná-lo a todos os outros textos significativos para cada um, reconhecer nele o tipo de leitura que 0 autor pretendia e dono da própria vontade, de entregar-se a essa leitura, ou rebelar-se contra ela, propondo outra não prevista.

Mais que promover a leitura, é preciso fazê-la de modo que o texto eleito para abordagem esteja de acordo com a capacidade de entendimento do alunado. Ou seja, trabalhar com textos / livros e outros que apresentem, dentre outros elementos: ideias compatíveis com a série em questão, com temas que acrescentem conhecimento considerando os conhecimentos prévios do alunado.

Para Silva (1987, p. 16), "Ler é interagir", é permitir ao aluno dialogar com o autor/emissor, valendo-se de suas próprias experiências conceituais, linguísticas, afetivas, atitudinais e outras. "Ao longo dessa interação, o sujeito recria esses referenciais pela dinamização do seu repertório. Nestes termos, o texto age sobre o leitor e, retrodinamicamente, o leitor age sobre o texto." (p. 16).

\footnotetext{
${ }^{3}$ Quando uma pessoa emite um comportamento, ela, anteriormente, recebeu um estímulo que trouxe consequências para aquele determinado contexto, influenciando no comportamento seguinte. Isso equivale dizer que, se a relação entre 0 estímulo recebido e a consequência gerada for boa, a pessoa tende a seguir o mesmo padrão comportamental, gerando uma cadeia de ações que também terá o mesmo efeito sobre as outras pessoas no mesmo contexto. Ver em: $<$ https://elidioalmeida.com/blog/terapia-comportamental-estimulo-e-resposta-o-homem-como-principal-agente-doscomportamentos-de-um-ambiente/s.
}

Revista de Ciências Humanas, Frederico Westphalen - RS, v. 22, n.2, p. 03-26, maio/ago. 2021. 
Ler é produzir sentido(s) A riqueza maior de um texto reside na sua capacidade de evocar múltiplos sentidos entre os leitores. Além disso, mesmo que um texto estabeleça limites aos processos de interpretação, quando ele inicia a sua circulação em sociedade, não existe forma de prever que sentido(s) ele terá. Assim, cabe aqui o entendimento de que repertórios diferentes produzirão diferentes sentidos ao texto, a menos que, conforme muitas vezes ocorre na escola, um único significado protocolar seja o privilegiado para efeito de reprodução e avaliação. (SILVA, 1987, p. 16).

Daí a importância de considerar o conhecimento prévio do leitor ao lhe apresentar determinada leitura. É preciso que o aluno dê sentido ao que lê, até porque os conhecimentos são diferentes de um aluno para o outro. E, ao considerar os conhecimentos prévios de seus alunos, o professor se abre -e aos alunos - a uma pluralidade de leituras e sentidos em relação a um mesmo texto.

"Ler é compreender e interpretar", e, partindo desse conceito, Silva afirma que o texto lido, compreendido e interpretado deve promover no aluno uma mudança a partir daquilo que o professor se dispôs em seu projeto pedagógico, considerando, para tanto, as competências de leitura a serem praticadas na série em questão.

Nessa mesma linha de raciocínio, é sabido que o aluno tem hoje, à sua disposição, uma gama de informações na mídia, e, para absorver o que realmente precisa para sua sobrevivência, para filtrar as informações que lhes são necessárias, é o professor quem vai auxiliá-lo, preparando-o para compreender as mais diversas organizações textuais presentes no universo da escrita, sempre inovando o processo da leitura com diferentes procedimentos pedagógicos. $\mathrm{E}$, considerando todos os conceitos de "ler" apresentados por Silva, é necessário ainda compreender as etapas da leitura.

Diante dessas considerações, ao docente cabe o desafio de ensinar o aluno a ler e despertar nele 0 desejo pela leitura nos anos iniciais do ensino fundamental, por esses representarem a base para a formação leitora dos anos seguintes. É nessa primeira fase da educação que se deve aguçar na criança 0 gosto e 0 interesse pela leitura, para, posteriormente trabalhar seus aspectos formais e intelectuais.

\section{RELAÇÃO ENTRE LEITURA E CONTAÇÃO DE HISTÓRIAS}

Nesta seção, buscamos discutir se contação de histórias incentiva a leitura das crianças, que tipo de leitura as crianças fazem e que tipo de leitura pode fazer com base na contação de histórias. Os principais autores para orientar essas premissas são Nelly Novaes Coelho, Regina Zilberman, Marisa Lajolo, entre outros.

Partindo do princípio de que a contação de histórias é um recurso lúdico, recorre-se a Santos e Jesus (2016, p. 03) para afirmar que Froebel criou brinquedos educativos com o objetivo de "desenvolver na criança os seus próprios dons, inteligência e sua essência humana.". Os jogos com 
regras eram para o referido educador alemão, uma excelente estratégia "mediadora no processo de apreensão do mundo pela criança, por meio da interiorização, como também no processo de conhecimento de si mesma pela criança (autoconhecimento), por meio da exteriorização." (ibdem).

Importante destacar que tanto os jogos como as brincadeiras deveriam ser monitoradas pelo professor, de modo a principalmente a manter próximas as crianças próximas a si e aos seus pares. Froebel gostava de jogos e brincadeiras em formas de círculo, que envolviam dança, música e movimento. Esse formato pode também ser usado no ensino e aprendizagem da leitura em se tratando da contação de histórias.

Os seguintes métodos e técnicas froebilianos auxiliam a criança a construir o conhecimento, pois, a partir delas, a criança terá noções de disciplina, de criação, de concretização na aprendizagem: Furar e recortar; fazer dobraduras; construções com tijolos cubos e objetos geométricos; modelagem; desenho; arte de colorir; aquarela; o cultivo de jardins; cuidados com os animais; ginástica; as marchas; rodas; cantos; poesias; histórias; conversas familiares; música e outros. Ao se observar tais métodos e técnicas pode inferir que a contação de história cabe em todas elas, conforme a atividade e os objetivos pretendidos pelo professor.

Nessa mesma perspectiva, na concepção de Montessori, segundo Rodrigues (2016), o aprender não deveria ser imposto, mas sim, cultivado / incentivado. $O$ ato de escrever / ler, por exemplo, deveria acontecer naturalmente e não como uma espécie de treinamento. $E$ isso poderia acontecer com a utilização de brinquedos, na fase da do "jardim da infância". Para a referida médica, filósofa e psicóloga, o melhor método é quando a criança descobre a habilidade de ler e escrever, a partir de sua necessidade, e, em seu brinquedo. E isso é possível por meio da contação de histórias, principalmente quando a criança / 0 aluno é ativo nesse processo.

O que se observa nessa primeira parte, em que se discute a relação entre leitura e contação de histórias, é que, ainda que seja pensada por muitos como somente uma brincadeira, a contação de histórias permite à criança, seja na educação infantil ou nas séries iniciais do ensino fundamental, a aprender a leitura de forma mais interpretativa, crítica, podendo até mesmo assimilar o foco do texto ao ouvir e contar uma história. Acredita-se que a contação de histórias incentiva a leitura das crianças a partir do momento em que esse tipo de atividade seja orientada para esse fim.

Esse acreditar é também defendido do estudo realizado por Oliveira e Júnior $(2019$, p. 16) quando dizem que:

A contação de histórias pode enriquecer as atividades pedagógicas cotidianas apresentadas às crianças, visando a oferecer uma gama de atividades diversificadas que estimulem 0 desenvolvimento integral da criança, envolvendo e promovendo a progressão da criatividade, 
concentração, oralidade, expressão, curiosidade, imaginação, socialização e integração do grupo.

A relação contação de histórias $x$ leitura será bem sucedida a partir do momento em que a primeira for pensada como recurso pedagógico e planejada como tal. Oliveira e Júnior (2019) expõem que em suas experiências pessoais e ao longo dos estágios obrigatórios, observaram o quanto as crianças aguardam ansiosas a contação de história, o "instante em que vão realizar uma viagem pela imaginação, quando suas emoções são despertadas." (p. 17). O despertar aqui é estímulo, é interesse aguçado.

Conforme afirmam Mateus et. all. (2015, p. 57), "Inúmeras são as possibilidades que o uso da contação de histórias em sala de aula propicia. Além de as histórias divertirem, elas atingem outros objetivos, como educar, instruir, socializar, desenvolver a inteligência e a sensibilidade." Essa afirmação encontra respaldo nas concepções de Vygotsky, Montessori e Froebel.

Mateus et. all. (2016, p. 57) citam Villardi (1997, p. 2) para firmarem que a literatura não tem recebido um estímulo adequado, e que a contação de histórias:

É uma alternativa para que os alunos tenham uma experiência positiva com a leitura, não uma tarefa rotineira escolar que transforma a leitura e a literatura em simples instrumentos de avaliação, afastando o aluno do prazer de ler. Porque, para formar grandes leitores, leitores críticos, não basta ensinar a ler. É preciso ensinar a gostar de ler. [...] com prazer, isto é possível, e mais fácil do que parece.

Esse pensamento de Villardi pode parecer absurdo em se tratando de crianças das séries iniciais do ensino fundamental. No entanto, é sabido que a criança tem o primeiro contato com a leitura I a contação de histórias antes mesmo antes de iniciar sua vida escolar, conforme afirmou Kleiman (2004). Mateus et. all. (2016, p. 58) expõem que o que se pode extrair dessa estratégia de ensino da leitura é que:

[...] utilizar a contação em sala de aula faz com que todos saiam ganhando, tanto 0 aluno, que será instigado a imaginar e criar, quanto o professor, que ministrará uma aula muito mais agradável e produtiva e alcançará o objetivo pretendido: a aprendizagem significativa. Além disso, as histórias ampliam o contato com o livro para que os alunos possam expandir seu universo cultural e imaginário e, através de variadas situações, a contação de histórias pode: intrigar, fazer pensar, trazer descobertas, provocar o riso, a perplexidade, o encantamento etc.

As descobertas levam o aluno à compreensão de mundo. E, em se tratando das descobertas pelo mundo da imaginação experimentada na contação de histórias, Mateus et. all. (2016) argumentam que essa estratégia "desperta no ouvinte a imaginação, a emoção e o fascínio da escrita e da leitura." (p. 58). A imaginação da criança é aguçada quando ela se sente desafiada (curiosidade), pelos sentimentos e emoções. A história seduz o ouvinte de forma a fazê-lo tomar gosto pela leitura. "A 
contação de história é fonte inesgotável de prazer, conhecimento e emoção, em que o lúdico e o prazer são eixos condutores no estímulo à leitura e à formação de alunos leitores." (p. 58).

Para discutir que tipo de leitura as crianças fazem e que tipo de leitora podem fazer com base na contação de histórias, é preciso ter em mente que o principal fator nesse processo é a escolha da história, seguido da forma como ela será contada (teatralidade: entonação de voz, caracterização e outros elementos), as condições que favorecerão essa estratégia. História é magia, é encantamento.

Oliveira e Júnior (2019) pesquisaram sobre os critérios da escolha dos livros e do melhor momento para contar histórias, como se organiza o ambiente e qual o tempo dedicado à essa atividade, e de que forma a professora instiga seus alunos à leitura. Estes mesmo autores, em suas observações no campo de estudo, viram que "as crianças buscavam saber qual era o livro escolhido, faziam sugestões e suposições, a professora revelava o livro a ser lido, as crianças sentavam, acomodam-se e aguardam com curiosidade o que estava por vir." (p. 18). Isso denota a contação de histórias como uma atividade motivadora, interessante, estimulante, que provoca na criança a vontade de ouvir o que o Autor da obra quer contar e assim, entrar no mundo imaginário e experimentar o que ele oferece.

Para Oliveira e Júnior (2019, p. 19):

Da mesma forma que o educador planeja suas aulas de língua portuguesa, matemática, geografia, seleciona as atividades que irá aplicar, faz as leituras da apostila ou livro didático para preparar a ministração da aula, o mesmo cuidado deve ser tomado na preparação para contar histórias, pois demonstrar intimidade com a leitura escolhida é fundamental. Dessa forma, a leitura será feita com convicção, com expressões e entonações adequadas aos momentos, esse cuidado é transmitido ao ouvinte, que pode ouvir e entrar no mundo da imaginação, vivenciando a história com encantamento, emoção e atenção. Interrupções como o gaguejar por desconhecer determinadas palavras, apresentar confusão ou surpresa no decorrer da leitura, isso pode tirar a atenção do ouvinte, trazendo-o de volta à sala de aula, quando deveriam estar mergulhados na narração.

Da citação acima compreende-se todo o zelo que se deve ter no preparo da atividade de contação de histórias.

A escolha do tipo de tipo de leitura, segundo Coelho (2000), deve ser de acordo coma faixa etária da criança. Porém, esta mesma autora destaca, para fomentar a aquisição da leitura mediante a contação de histórias, que essa deve ser necessariamente enriquecedora, bem preparada. E, em se tratando da educação infantil, o melhor é trabalhar a leitura com uso de imagens e figuras ilustrativas compondo bem o espaço lúdico em sala de aula (ambientação da história a ser contada, ouvida, imaginada...).

Oliveira e Júnior (2019, p. 19) concordam com Coelho (2000) ao afirmarem que a escolha da leitura deve ser bem criteriosa considerando:

Revista de Ciências Humanas, Frederico Westphalen - RS, v. 22, n.2, p. 03-26, maio/ago. 2021. 
A categoria a qual o grupo se aproxima, facilitando o entendimento dos alunos sobre a leitura apresentada. Caso contrário, a história causará tédio, falta de atenção, inquietude e dispersão. A leitura desperta sentimentos, emoções, afetividade e na infância também auxilia na estimulação do imaginário, criando uma comparação com as situações vivenciadas, facilitando a compreensão da realidade.

Uma vez mal planejada, uma vez entediante, dificilmente a criança se sentirá motivada à mesma atividade. Na concepção de Coelho (2000), a leitura é uma conquista, é um tomar posse da informação que o texto / a história apresenta. E esse processo precisa, segundo a pesquisadora, ser dinâmico, deixando claros os acontecimentos do texto e das imagens que eles trazem. Deve ser um tipo de leitura que não só aguce a curiosidade e interesse da criança, mas, também, provoque nela atitude crítica.

"A literatura infantil é, antes de tudo, literatura; ou melhor, é arte: fenômeno de criatividade que representa o mundo, o homem, a vida, através da palavra. Funde sonhos e a vida prática, o imaginário e o real, os ideais e sua possível/impossível realização [...]", afirma Coelho (2000, p. 27). Tomando essa citação coo referência, compreendemos que escolher uma leitura para trabalhar como recurso pedagógico para o ensino da leitura é, antes de tudo, sentir o que ela vai trazer não só de conhecimento, mas, ainda, o que ela contribuirá na transformação do ouvinte, do leitor - o que de fato deverá ser absorvido com o centro da história.

A esse respeito, Lajolo e Zilberman (2002) afirmam que a literatura infantil é pensada como bem cultural da Psicologia Infantil, da Pedagogia e também da Pediatria. Esse pensamento denota que a literatura está a serviço da formação da criança antes e depois de sua inserção na Educação. E que faz parte do processo da construção do saber da e pela criança. Em sua pesquisa, Oliveira e Júnior (2019, p. 20) observaram que:

\begin{abstract}
A atividade de contação de histórias, por meio da literatura infantil é importante no desenvolvimento da criança por diversos fatores, como no processo de aquisição da leitura e escrita. As crianças que possuem contato com histórias desenvolvem a imaginação, a capacidade de discernimento, a crítica e é um grande estímulo à criatividade. Por meio das histórias, as crianças são instigadas a fantasiar, criar, imaginar, tudo isso a partir das ideias lançadas pelo narrador da história.
\end{abstract}

Além disso, os autores acima citados observaram que a professora também faz uso da contação de histórias e a professora atua para controlar a agitação das crianças, visando a acalmá-las para o início de uma próxima atividade.

Dinorah (1995) afirma que, para as crianças, deem-se oferecer textos / histórias próprias da literatura infantil tanto na Educação Infantil como nas séries iniciais do Ensino fundamental. Esta mesma autora referencia Zayra Petry para afirmar que a Literatura Infantil "é a própria expressão literária, com valores e características que se ajustam ao desenvolvimento intelectual e psicológico da 
criança. É o conjunto de obras de ficção, poesia, teatro, biografias, viagens, aventuras reais, escritas para as crianças e ajustadas à sua psicologia.".

Em se tratando da Literatura, conforme Martins e Galhart (2015, p. 04), esta, por sua natureza:

Traduz o homem em sua essência e influencia de maneira significativa em sua formação, desempenhando duas funções essenciais: a função psicológica e a função formadora. A função psicológica está atrelada a uma característica peculiar do ser humano que se refere à necessidade de transição entre o mundo real e 0 universo ficcional, como algo vital ao ser humano. (...) O leitor de uma obra literária sofre influências da gama de informações que a mesma traz, provocando diversas reações que estão fora do seu controle, portanto, eis a razão do autor expor a função formadora, que confere à literatura um caráter formativo e educativo.

Isso implica reconhecermos que uma obra literária traz implícito o olhar do autor do texto ao mesmo tempo em que acende no leitor seu próprio olhar sobre o que vê/ouve, de forma benéfica. 0 caráter formativo do leitor pode ser potencializado à medida que este tem contato com textos literários, sobretudo aqueles que são dirigidos ao infante, como é o caso da literatura infantil.

Complementando, Busatto (2003) explica que as histórias são fontes de sabedoria e exercem o papel formador da identidade, pelo conhecimento de vida que trazem/propõem, pelos valores culturais e pelas tradições que resgatam. Além disso, entre outros benefícios, a contação de histórias no ensino da leitura desenvolve na criança a capacidade de dar sequência lógica aos fatos; estimula o gosto pela leitura e o contato mais intenso com ela, aumenta o vocabulário, desenvolve a linguagem oral e escrita; amplia o horizonte da criança e seu conhecimento de mundo.

Os contos de fada são muito usados na fase anterior ao ingresso da criança na Educação e permanece pelo menos até as séries iniciais do ensino fundamental, revelando-se como excelentes promovedores do desenvolvimento dos aspectos sociocognitivo e afetivo da criança, principalmente dos três aos seis anos. De acordo com Mateus et. al. (2016, p. 58):

As histórias narradas sempre acompanharam a vida do homem em sociedade. Por meio delas, foi possível a preservação da cultura. Durante muito tempo, foram a única fonte de aquisição e transmissão do conhecimento. A narrativa é a arte de contar histórias que é tão antiga quanto o homem. A contação de história estimula a imaginação, retrata pessoas, lugares, acontecimentos, desejos e sonhos, favorecendo o processo da aprendizagem.

Para os pesquisadores, os contos de fada podem ser narrados da forma mais simples possível, mantendo-se sua estrutura, partindo de um problema (começo), buscando soluções (meio) e a solução propriamente dita (fim). De acordo com Mateus et. all. (2016), A Bela Adormecida (de Charles Perrault) é um clássico dos contos de fada. Assim como a estória de João e Maria (de Hansel e Gretel). Outros contos de fadas de Perrault que mais se destacaram foram: Barba Azul, O Pequeno Polegar, Rapunzel, Cinderela e O Gato de Botas. Para Abramovich (1997, p. 17): 
A leitura de histórias permite que o leitor descubra o mundo imenso dos conflitos, dos impasses, das soluções que todos nós vivemos e atravessamos através dos problemas que vão sendo defrontados, enfrentados (ou não), resolvidos (ou não) pelas personagens de cada história (cada um ao seu modo).

Significa afirmar que as leituras, ainda que faça parte de um mundo imaginário, podem auxiliar as crianças em determinados problemas.

Busatto (2003) ensina algumas considerações básicas de contação de histórias que podem auxiliar o professor narrador a encantar suas crianças. A primeira é o professor "curtir" a história, ou seja, envolver-se nela e vibrar ao contá-la, mostrar-se interessado e provocar nas crianças esse mesmo interesse. A segunda é ler o que está escrito no livro, sem distorções, pois, ao fazê-lo, correria o risco de adaptar o texto e fazê-lo perder o sentido que seu autor tinha como objetivo. 0 texto literário deve ser apresentado às crianças tal como escrito.

A terceira, de acordo com Busatto (2003), é o narrador não explicar demais a história, mantendo-se sua função de desenvolver o mistério. A quarta é, ao preparar uma história a ser contada, o professor se lembrar de que uma história é um ponto de encontro, um ponto de partida para o qual ele pode dar sequência em outras atividades: teatro, atividades manuais (massinha, cerâmica, jardim, horta,...), desenho e outras.

A quinta é concluir a contação de história, deixando clara a "moral da história" ou as morais da história, fazendo com que, a partir delas, as crianças possam experimentar as sensações, os sentimentos, a imaginação durante e depois da história contada. E, dentro do possível, trazer para sua vida essa moral.

Assim, a relação entre leitura e contação de histórias exprime-se na forma de o professor pensar como se pode expor uma história à criança (teatro, leitura do próprio livro e outros), a intencionalidade e o tempo destinado a essa atividade, pois o uso de recursos lúdicos que envolvem a oralidade é um dos eixos de estímulo à leitura e à formação de leitores.

\section{DIRETRIZES PARA LEITURA NA ESCOLA: A BNCC}

Segundo a BNCC - Base Nacional Comum Curricular (MEC, 2019), é preciso ampliar as possibilidades de construção do conhecimento aos alunos, de modo que não se perca o que eles apreenderam antes de chegar ao Ensino Fundamental, seja na educação escolar, seja no âmbito familiar e/ou social. E isso se faz por meio da leitura e da escrita. De acordo com a BNCC (MEC, 2019, p. 70): 
Leitura no contexto da BNCC é tomada em um sentido mais amplo, dizendo respeito não somente ao texto escrito, mas também a imagens estáticas (foto, pintura, desenho, esquema, gráfico, diagrama) ou em movimento (filmes, vídeos etc.) e ao som (música), que acompanha e cossignifica em muitos gêneros digitais.

Notamos que, em se considerando ao que preza a BNCC, a exigência da formação leitura e como esta se deve dar alia-se à necessidade de formação docente para a abordagem da leitura. Da mesma forma, é preciso aparato teórico-prático sobre leitura nos anos iniciais para o trabalho docente. Se considerarmos a quantidade de publicações específicas sobre a relação entre contação de histórias e formação leitora, podemos afirmar que o número de trabalhos ainda é escasso.

A contação de histórias aparece na BNCC (MEC, 2019) na Prática da Linguagem, no campo da vida cotidiana, que prevê a participação do aluno em diferentes situações de leitura e diferentes espaços: espaço doméstico e familiar, escolar, cultural e profissional. Nesse campo, encontram-se gêneros textuais, como: "agendas, listas, bilhetes, recados, avisos, convites, cartas, cardápios, diários, receitas, regras de jogos e brincadeiras." (p. 96).

Aparece ainda mais especificamente (a contação de história) no campo de Leitura/escuta (compartilhada e autônoma), que compreende os seguintes objetos do conhecimento: Formação do leitor literário Leitura colaborativa e autônoma Apreciação estética/Estilo Formação do leitor literário/Leitura multissemiótica.

Aparece no campo Artístico-literário - Habilidade EF15LP16, que significa o aluno: ler e compreender, em colaboração com os colegas e com a ajuda do professor e, mais tarde, de maneira autônoma, textos narrativos de maior porte como contos (populares, de fadas, acumulativos, de assombração etc.) e crônicas. Conforme a BNCC (MEC, 2019, p. 24):

\begin{abstract}
Essa habilidade pressupõe um complexo trabalho envolvendo o planejamento de situações de leitura/escuta, de modo frequente, para que o estudante possa desenvolver diferentes estratégias de leitura de textos narrativos em colaboração com os colegas e com o educador. Além de trabalhar com as características de gêneros literários narrativos mais extensos. É possível estabelecer relações com a habilidade complementar EF15LP15, com o objetivo de propiciar aos estudantes o reconhecimento de textos literários como um patrimônio artístico da humanidade. As sugestões, portanto, preveem a progressão da habilidade, considerando 0 ano e a complexidade dos textos e dos gêneros textuais. Recomenda-se a elaboração de projetos permanentes de contação de histórias em que os estudantes possam ouvir narrativas, bem como atuar como contadores.
\end{abstract}

Tudo isso, sem a necessidade de conhecimento prévio pelo aluno. E, a princípio, pode parecer muito complexo, já que se trata das séries iniciais do Ensino Fundamental.

Toda leitura deve ter uma finalidade, ser tratada pelo professor como uma atividade que traz saberes sobre o homem e sobre o mundo - de modo geral e particular. As histórias contadas, para desenvolver esses saberes, estimular a participação do leitor precisa de alguma forma trazer um 
mínimo do retrato da realidade do aluno. Ainda que sejam fantasias sendo contadas. A partir da inserção / participação da criança no texto, ela poderá expressar a forma é sensível ao que lhe está sendo contado. Aí a oportunidade da identificação do que ela é ou faz parte, e de como ela pode(rá) agir diante de determinadas situações.

Ao se pensar no desenvolvimento de competências e habilidades a partir da literatura, em especial da contação de histórias, faz-se necessário pensar os textos e obras literárias que permitam o diálogo do leitor / do ouvinte com o aquilo que está sendo lido / ouvido, contado. Caso contrário, a leitura não passará de ser o cumprimento de hora-aula, sem a finalidade educativa, social que ela pode gerar.

A contação de histórias aparece ainda mais especificamente, no Eixo da Oralidade Habilidade EF15LP19, que significa o aluno: "Recontar oralmente, com e sem apoio de imagem, textos literários lidos pelo professor.", conforme apresenta a BNCC (MEC, 2019, p. 96).

Conforme 0 Quadro 3, as Competências relacionadas à área de Linguagens são: Competências Gerais 3 e 4; Competências da Área 2, 3 e 5; Competências Específicas 3 e 5. Segundo a BNCC (MEC, 2019, p. 78), o Eixo da Oralidade:

Compreende as práticas de linguagem que ocorrem em situação oral com ou sem contato face a face, como aula dialogada, web conferência, mensagem gravada, seminário, debate, programa de rádio, entrevista, declamação de poemas (com ou sem efeitos sonoros), peça teatral, apresentação de cantigas e canções, playlist comentada de músicas, contação de histórias, diferentes tipos de podcasts e vídeos, dentre outras. Envolve também a oralização de textos em situações socialmente significativas e interações e discussões envolvendo temáticas e outras dimensões linguísticas do trabalho nos diferentes campos de atuação. 0 tratamento das práticas orais compreende. (Grifo da pesquisadora)

QUADRO 3 - Competências da Área de Linguagens séries iniciais EF 


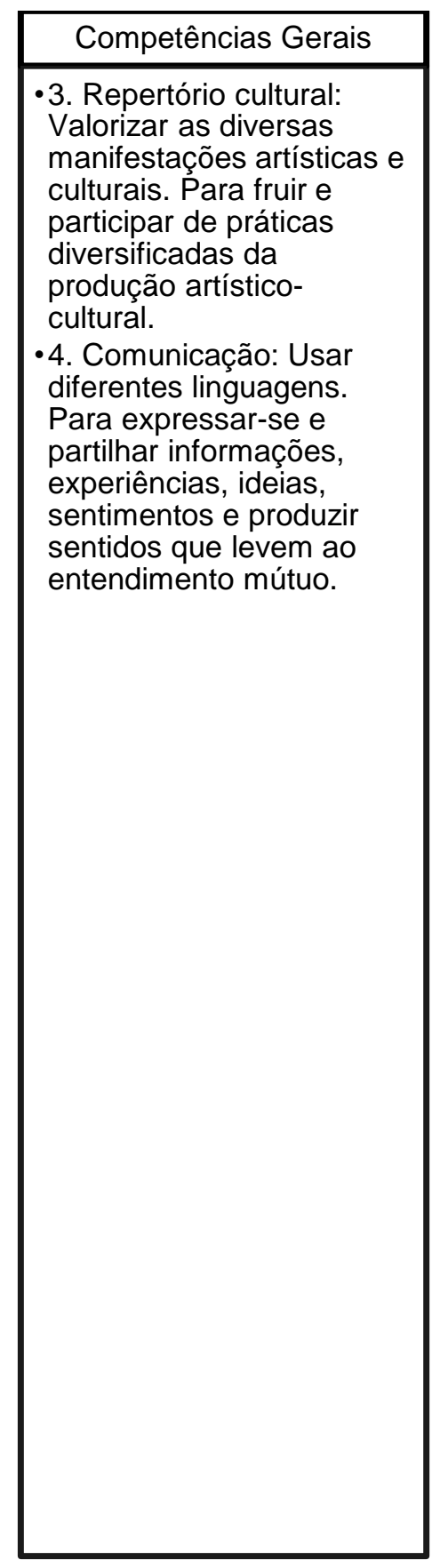

\begin{tabular}{|l|}
\hline \multicolumn{1}{|c|}{ Competências da Área } \\
\hline -2. Conhecer e explorar \\
diversas práticas de \\
linguagem (artísticas, \\
corporais e linguísticas) \\
em diferentes campos da \\
atividade humana para \\
continuar aprendendo, \\
ampliar suas \\
possibilidades de \\
participação na vida \\
social e colaborar para a \\
construção de uma \\
sociedade mais justa, \\
democrática e inclusiva. \\
-3. Utilizar diferentes \\
linguagens - verbal (oral \\
ou visual-motora, como \\
Libras, e escrita), \\
corporal, visual, sonora e \\
digital -, para se \\
expressar e partilhar \\
informações, \\
experiências, ideias e \\
sentimentos em \\
diferentes contextos e \\
produzir sentidos que \\
levem ao diálogo, à \\
resolução de conflitos e à \\
cooperação. \\
-5. Desenvolver o senso \\
estético para reconhecer, \\
fruir e respeitar as \\
diversas manifestações \\
artísticas e culturais, das \\
locais às mundiais, \\
inclusive aquelas \\
pertencentes ao \\
patrimônio cultural da \\
humanidade, bem como \\
participar de práticas \\
diversificadas, individuais \\
e coletivas, da produção \\
artístico-cultural, com \\
respeito à diversidade de \\
saberes, identidades e \\
culturas. \\
\hline
\end{tabular}

\begin{tabular}{l}
\hline Competências Específicas \\
\hline -3. Ler, escutar e produzir \\
textos orais, escritos e \\
multissemióticos que \\
circulam em diferentes \\
campos de atuação e \\
mídias, com \\
compreensão, autonomia, \\
fluência e criticidade, de \\
modo a se expressar e \\
partilhar informações, \\
experiências, ideias e \\
sentimentos, e continuar \\
aprendendo. \\
-5. Desenvolver o senso \\
estético para reconhecer, \\
fruir e respeitar as \\
diversas manifestações \\
artísticas e culturais, das \\
locais às mundiais, \\
inclusive aquelas \\
pertencentes ao \\
patrimônio cultural da \\
humanidade, bem como \\
participar de práticas \\
diversificadas, individuais \\
e coletivas, da produção \\
artístico-cultural, com \\
respeito à diversidade de \\
saberes, identidades e \\
culturas. \\
\end{tabular}

Fonte: Adaptado de BNCC (2019).

A BNCC (MEC, 2019, p. 08) define competência como "a mobilização de conhecimentos (conceitos e procedimentos), habilidades (práticas, cognitivas e socioemocionais), atitudes e valores para resolver demandas complexas da vida cotidiana, do pleno exercício da cidadania e do mundo do trabalho.". Competência, em uma linguagem mais simples, compreende um conjunto de conhecimentos e habilidades que "expressam as aprendizagens essenciais que devem ser asseguradas aos alunos 
nos diferentes contextos escolares." (p. 29). Na BNCC, o desenvolvimento de competências ocorre pela articulação de várias habilidades, de maneira progressiva.

Dessa forma, ao se considerar a BNCC como norteadora das práticas docentes, cabe pensar em como criar condições para implantá-la na área de linguagens nos anos iniciais do Ensino Fundamental. E isso implica metodologia e proposições didáticas.

\section{ROTEIRO PARA CONTAÇÃO DE HISTÓRIA E PRÁTICA LEITORA}

Na busca por apresentação de proposições didáticas, o primeiro passo consiste na elaboração de um roteiro que possa guiar as atividades pensadas para a formação leitora. Nesse sentido, procuramos envolver as etapas de leitura abordadas no referencial teórico, as habilidades a serem desenvolvidas e ainda as atividades basilares que podem compor a aplicação das ações propostas.

Dessa forma, sintetizamos, com atenção aos estudos de Gonçalves (2008), estratégias de leitura que acreditamos ser adequadas para a elaboração das proposições didáticas focadas na atividade inicial, mas não exclusiva, de contação de histórias.

QUADRO 4 - Estratégias de leitura e contação de história

\begin{tabular}{|l|l|}
\hline \multicolumn{1}{|c|}{ Estratégia } & \multicolumn{1}{c|}{ Objetivo } \\
\hline Compreensão global da história contada & $\begin{array}{l}\text { Determinar as ideias principais do texto, consiste } \\
\text { em separar ideias principais de secundárias. }\end{array}$ \\
\hline Compreensão detalhada da história contada & $\begin{array}{l}\text { "Sumariar a informação contida no texto", ou } \\
\text { seja, resumir ou parafrasear o texto, explicitando } \\
\text { o ponto de vista. }\end{array}$ \\
\hline contato & $\begin{array}{l}\text { Realizar inferências sobre o texto, mobilizando } \\
\text { conhecimento prévios do aluno-leitor e pistas } \\
\text { linguísticas. }\end{array}$ \\
\hline Interpretação da história & $\begin{array}{l}\text { Elaborar "questões pertinentes sobre o texto", } \\
\text { avaliando o significado do texto para o aluno, a } \\
\text { profundidade da compreensão do texto e a } \\
\text { ralação do texto com o contexto sociocultural. }\end{array}$ \\
\hline Monitoramento de leitura & $\begin{array}{l}\text { Refletir sobre os pensamentos dos estudantes e } \\
\text { a eventual mudança de perspectiva com base na }\end{array}$ \\
\hline Revista de Ciências Humanas, Frederico Westphalen - RS, v. 22, n.2, p. 03-26, maio/ago. 2021. \\
Recebido em: 03/05/2021
\end{tabular}


Essas diferentes estratégias de leitura serão abordadas em cada proposição, que segue um roteiro.

QUADRO 5 - Roteiro da proposição

\begin{tabular}{|c|c|}
\hline Item do Roteiro & Objetivo \\
\hline Tema & $\begin{array}{l}\text { Definição dos temas norteadores da prática de } \\
\text { contação de história, com foco na obra literária } \\
\text { selecionada, e em atividades de leitura. }\end{array}$ \\
\hline Objetivos & $\begin{array}{l}\text { Delimitação dos objetivos previstos para } \\
\text { proposição a fim de indicar a finalidade maior a } \\
\text { ser alcançada na execução da proposta. }\end{array}$ \\
\hline Habilidades e Competências & $\begin{array}{l}\text { Indicação de habilidades e competências, } \\
\text { conforme a BNCC } \\
\text { fundamental, as quais podem ser reveladas por } \\
\text { meio da execução das atividades propostas. }\end{array}$ \\
\hline Público-alvo & Alunos dos anos iniciais do Ensino Fundamental. \\
\hline Recursos & $\begin{array}{l}\text { Registro dos recursos humanos e materiais } \\
\text { utilizados para } 0 \text { desenvolvimento das } \\
\text { atividades. }\end{array}$ \\
\hline Atividades & $\begin{array}{l}\text { Explanação das atividades sugeridas, seguindo } \\
\text { contação de história e prática leitora conforme } \\
\text { estratégias de leitura apontadas por Gonçalves } \\
\text { (2008). }\end{array}$ \\
\hline Avaliação & $\begin{array}{l}\text { Indicação de forma para avaliação e } \\
\text { autoavaliação das atividades propostas. }\end{array}$ \\
\hline Referências & $\begin{array}{l}\text { Apresentação de referências para execução das } \\
\text { atividades e de indicação de leituras para } \\
\text { ampliação dos saberes e práticas docentes } \\
\text { sobre o tema. }\end{array}$ \\
\hline
\end{tabular}

Fonte: elaborado pela autora 
É importante frisar dois pontos que nos parecem relevantes sobre o roteiro. 0 primeiro referese ao fato de que não discriminamos uma etapa específica dos anos iniciais do Ensino Fundamental, uma vez que, conforme projeto pedagógico da escola, perfil dos alunos e interesses por leitura, as expectativas e necessidades podem variar de um ano para outro. Logo, não entendemos ser oportuno direcionar uma série específica dessa etapa escolar para a indicação das proposições didáticas. Entendemos que cabe ao professor observar a adequação das atividades à sua turma no momento de aplicação das práticas de contação e de leitura propostas.

Outro ponto a destacar sobre o roteiro é a ideia segundo a qual o que apresentamos é uma sugestão para o planejamento das atividades docentes e discentes, mas não uma imposição de roteiro e de ações de contação de histórias e práticas leitoras como algo definido e estabelecido sem possibilidades de ajustes ou modificações. Partimos do pressuposto de que as sequências didáticas podem se constituir um norte para o trabalho do professor interessado em atividades de contação de histórias e sua relação com a formação leitora.

Por fim, registramos ainda que o roteiro busca estabelecer uma relação direta entre a proposta deste trabalho de pesquisa e o desenvolvimento de habilidades que são esperadas tanto em relação à leitura quanto em relação ao papel que a literatura pode desempenhar na formação humana e sociocultural, sobretudo de estudantes que podem, talvez apenas na escola, terem contato com a arte literária.

A fim de ilustrar o roteiro, apresentamos uma atividade que tem como objeto de contação de histórias e prática leitora o livro Menina bonita dos laços de fita, de Ana Maria Machado. A seguir a proposição elaborada.

Tema: Universo da criança na família

\section{Objetivos:}

- Compreender a obra Menina Bonita do Laço de Fita, de modo a apreender a sua estrutura e forma narrativa;

- Identificar o tema central da obra e o papel da família da personagem central na acolhida das angústias apresentadas pela criança;

- Incentivar o gosto pela leitura de histórias narradas e sua compreensão;

- Abordar a valorização social de grupos étnicos, preconceito racial, aceitação das diferenças e exercício de alteridade.

\section{Habilidades e competências:}

- Valorizar as diversas manifestações artísticas e culturais; 
- Desenvolver o senso estético para reconhecer, fruir e respeitar as diversas manifestações artísticas e culturais, das locais às mundiais, inclusive aquelas pertencentes ao patrimônio cultural da humanidade, bem como participar de práticas diversificadas, individuais e coletivas, da produção artístico-cultural, com respeito à diversidade de saberes, identidades e culturas.

- Ler, escutar e produzir textos orais, escritos e multissemióticos que circulam em diferentes campos de atuação e mídias, com compreensão, autonomia, fluência e criticidade, de modo a se expressar e partilhar informações, experiências, ideias e sentimentos, e continuar aprendendo.

Público-alvo: alunos dos anos iniciais do Ensino Fundamental

Recursos: livro impresso, caderno, papel, caneta

\section{Atividades:}

1) O professor deve iniciar a atividade, apresentando o livro e a autora de forma a contextualizar a obra a ser contada. Depois, deve contar a história, dispondo do livro impresso e de espaço organizado na sala de aula para a contação.

2) Depois de contada a história. O professor pode realizar alguns questionamentos com o objetivo de estimular os estudantes a analisar e a compreender a narrativa de forma global:
- Com quem as crianças se parecem em termos físicos? E comportamentais?
- E os filhotes de animais com que se parecem?
- De que forma a história representa a realidade de determinadas crianças?
- Você conhece alguma criança que viveu situação semelhante à da menina da história?
- Se você fosse a menina, teria a mesma percepção dela sobre a cor?
- Se você fosse a mãe da menina, teria a mesma atitude dela?
- Se você fosse o coelho, teria o mesmo desejo dele?

3) Agora, é o momento de desvendar a obra. Como você sabe, a história é uma narrativa e toda narrativa conta uma história e apresenta alguns elementos básicos. Vamos reconhecê-los? Você pode identificar os elementos da narrativa, preenchendo, por meio de um diálogo entre professores e a turma, o quadro abaixo em seu material de estudo:

\begin{tabular}{|l|l|}
\hline Quem conta a história é o narrador. & \\
Como você define o narrador da história: ele & \\
apenas conta a história ou conta e emite & \\
julgamento sobre os personagens? & \\
\hline Quem "vive" a história são os personagens. & \\
\hline
\end{tabular}




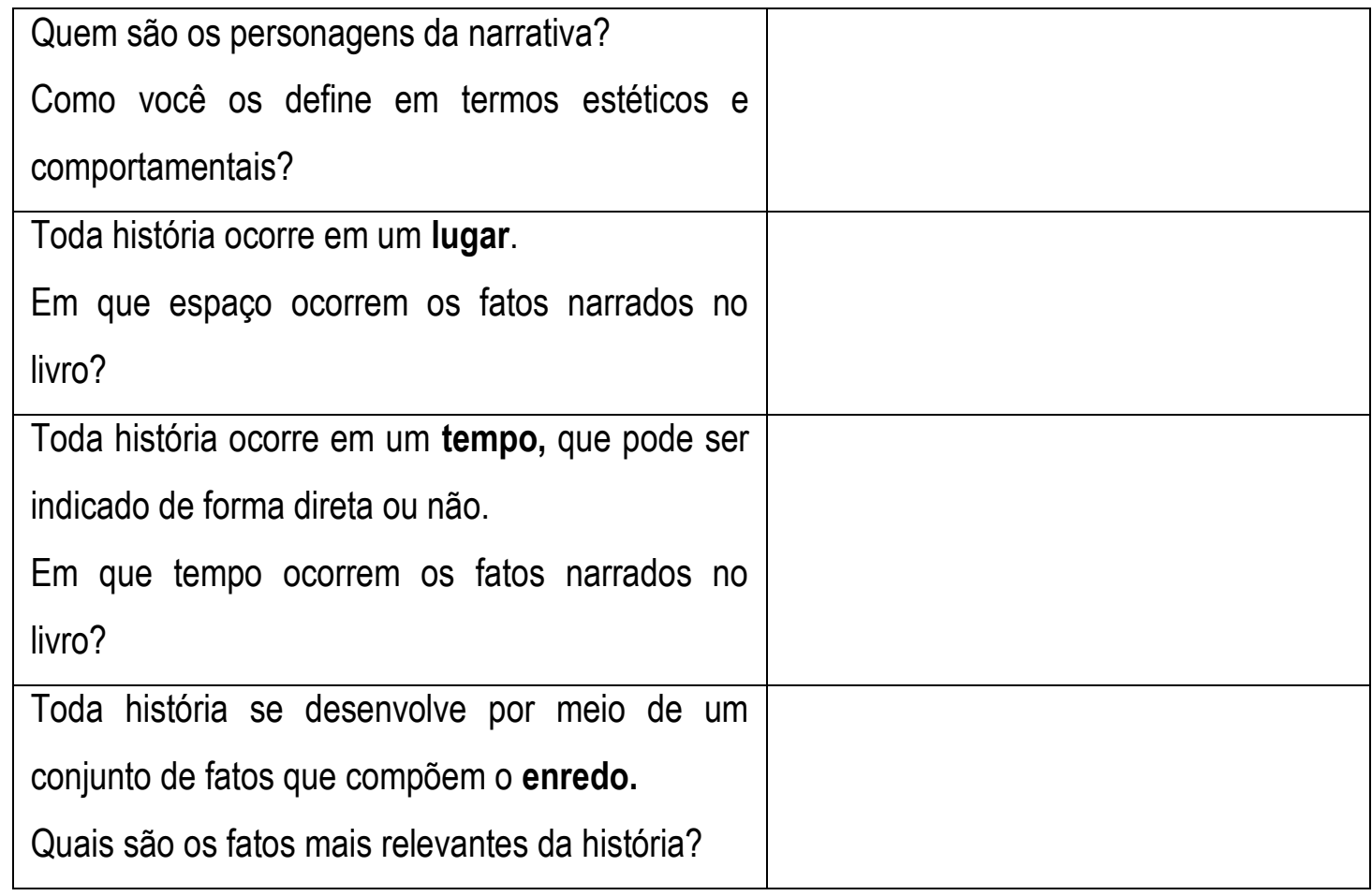

4) A história contada está reproduzida em um livro que mescla linguagem verbal e não verbal. Manuseie o livro e analise as ilustrações para discutir em grupo:

- O que as imagens indicam sobre os sentimentos da menina em relação a sua própria cor?

- O que as imagens indicam sobre reação da mãe diante da avaliação da menina em relação a sua própria cor?

- O que as imagens indicam sobre os sentimentos e desejos do coelho em relação a sua própria cor?

- Para você, as imagens são elementos importantes no livro? Por quê?

5) Uma narrativa sempre aborda um tema em especial. Para você qual é o tema de Menina Bonita do Laço de Fita?

6) Se você tivesse que resumir em uma frase toda a história, o que você escreveria?

7) O fato de a menina ter dificuldades iniciais relativas à aceitação de seu cabelo indica o quê?

8) O fato de o coelho gostar de uma cor de pelo diferente da sua indica o quê?

9) Você acha que é preciso mudar a cor de pele ou de pelo para ser aceito?

10) Se você convivesse com a menina da história, que conselho daria a ela? Se você fosse o coelho da história, que conselho daria a ele?

11) Agora é a vez de você expressar as suas impressões sobre a história narrada. Elabore, de forma individual, um cartaz, indicando o que você entende e pensa sobre cada um dos tópicos: 


\begin{tabular}{|c|c|c|c|}
\hline Cor e preconceito & $\begin{array}{ll}\text { Negro } & \text { na } \\
\text { literatura } & \end{array}$ & $\begin{array}{l}\text { Valorização das } \\
\text { diferenças }\end{array}$ & $\begin{array}{l}\text { Exercício } \\
\text { alteridade }\end{array}$ \\
\hline
\end{tabular}

12) Exponha, em um mural da sala, o seu cartaz, explicando para colegas e professora a sua percepção sobre os tópicos anteriores e como a obra lhe permite pensar sobre cada um dos temas.

Avaliação: a avaliação pode ser realizada com base na observação ao desenvolvimento das atividades propostas assim como em relação à interação dos estudantes com a obra e suas posições quanto aos temas abordados.

\section{Referências:}

COELHO, Nelly Novaes. Literatura infantil: teoria, análise, didática. 1. ed. São Paulo: Moderna, 2000. GUIMARÃES, Geni. A cor da ternura. São Paulo, FTD, 1998.

MACHADO, Ana Maria. Menina bonita do laço de fita. 7. ed. São Paulo: Ática, 2000.

OLIVEIRA, Maria Anória de J. Personagens negros na Literatura Infanto-Juvenil: há muito fazer-dizer, há muito de palavra-ação. In.: SILVIA, Márcia Tavares;

RODRIGUES, Etiene Mendes. (Orgs). Caminhos da Leitura Literária: Propostas e Perspectivas de um Encontro. Campina Grande: Bagagem, 2009. P. 156-176.

RIBEIRO, Djamila. Pequeno manual antirracista. São Paulo: Companhia das Letras, 2019.

\section{CONSIDERAÇÕES FINAIS}

Destaca-se que este estudo reflete sobre a contação de histórias como estratégia para o estímulo da leitura nos anos iniciais do Ensino Fundamental. A principal potencialidade das propostas da formação do leitor, no que diz respeito à contação de histórias, está no fato de que essa estratégia faz parte da maioria das pessoas desde a infância, em família. Além disso, há uma gama de textos e obras literárias que motivam o aluno a ler, como as referenciadas para a sequência didática. Já entre as fragilidades, pode-se citar: ambiente nem sempre propício à leitura; textos de difícil compreensão; desprezo do professor em relação aos elementos fundamentais da leitura, valendo-se de materiais pobres (livros, textos, ambiente e outros).

Para explorar a contação de histórias nos anos iniciais para a formação de leitores, o primeiro passo é o professor saber que não se trata de uma brincadeira sem sentido, um passatempo, mas sim, 
uma rica estratégia de ensino e aprendizagem da leitura. Para esse fim, a atividade precisa ser bem elaborada e orientada, de forma que ao adentrar ao mundo da imaginação o aluno tenha despertadas suas emoções e interesse pelo que ouve. A contação de histórias propicia mais que diversão: educa; instrui; auxilia na socialização, no desenvolvimento da inteligência e da sensibilidade. A partir daí, o aluno estará ampliando seu conhecimento, fazendo descobertas, tornando-se encantado pelo mundo que o rodeia. E o melhor, isso e muito mais, pelo ato e hábito de ler, de contar e ouvir histórias, de interpretar o que ouve e o que lê.

Nesse sentido, este artigo apresentou uma proposta de sequência didática com foco no livro Menina bonita dos laços de fita, de Ana Maria Machado. As proposições apresentadas são exercícios de pensar a formação leitora e de fomentar uma atuação com a literatura como meio de leitura e de desenvolvimento de uma formação mais humanizada e atenta a demandas contemporâneas contrárias a práticas de exclusão, preconceito e discriminação. Não intencionam ser as únicas possibilidades de abordagem dos textos, mas possibilidades de sua exploração nos anos iniciais do Ensino Fundamental.

Alcançados os objetivos, conclui-se que esse estudo permite compreender as questões teóricocríticas acerca de contação de histórias e leitura na etapa inicial do Ensino Fundamental, e também organizar uma proposta de atividade que auxilie professores a tornar a contação de histórias mais do que uma ação lúdica no horizonte da preparação o aluno, mas também uma possibilidade de despertar o gosto pela leitura e a formação de bons leitores.

\section{REFERÊNCIAS}

ABRAMOVICH, Fanny. Literatura infantil: gostosuras e bobices. São Paulo: Scipione, 1997.

BAMBERGER, Richard. Como incentivar o hábito de leitura. São Paulo: Ática, 2000.

BATISTA, Antônio Augusto Gomes. Práticas de Leitura. Centro de Estudos e Pesquisas em Educação, Cultura e Ação Comunitária - CENPEC, 2019. Disponível em:

<http://www.ceale.fae.ufmg.br/app/webroot/glossarioceale/verbetes/praticas-de-leitura>. Acesso em: 17 mar. 2020.

BRASIL/MEC. Parâmetros Curriculares Nacionais. 3. ed. Brasília - DF: MEC, 2001.

BRASIL/MEC. Parâmetros Curriculares Nacionais: Língua Portuguesa. Secretaria de Educação Fundamental. Secretaria de Educação Fundamental. Brasília - DF: MEC, 1997.

BUSATTO, Cléo. Contar e Encantar: Pequenos Segredos da Narrativa. $3^{\text {a }}$ ed. Petrópolis - RJ: Vozes, 2003.

COELHO, Nelly Novaes. Literatura infantil: teoria, análise, didática. São Paulo: Moderna, 2000. 
GONÇALVES, Suzana. Aprender a ler e compreensão do texto: processos cognitivos e estratégias de ensino. In: Revista Iberoamericana de Educación - No. 46, jan.- abr. 2008.

KLEIMAN, Angela B. Projetos de Letramento na Educação Infantil. Revista Caminhos em Linguística Aplicada, UNIYTAU, vol.1, $n^{\circ}$ 1, 2009, p. 1-10. Disponível em: <www.unitau.br/caminhosla>. Acesso em: 18 out. 2020.

KLEIMAN, Ângela. Oficina de leitura: teoria \& prática. 10. ed. Campinas: 2004.

KLEIMAN, Angela. Oficina de Leitura: Teoria e Prática. 9. ed. Campinas - SP: Pontes, 2002.

LAJOLO, Marisa; ZILBERMAN, Regina. Literatura Infantil Brasileira: História \& Histórias. São Paulo: Ática, 2002.

MEC. BNCC - Base Nacional Comum Curricular. Ministério de Educação - MEC / Conselho Nacional de Secretários de Educação - CONSED / União Nacional dos Dirigentes Municipais de Educação - UNDIME, 2019. Disponível em:

<http://basenacionalcomum.mec.gov.br/images/BNCC_20dez_site.pdf >. Acesso em: 21 mar. 2020.

OLIVEIRA, Samantha Aniceto de; JÚNIOR, Claudio Roberto Antunes Scherer. A contação de histórias no ensino fundamental: fundamentos e planejamentos. Cadernos da Pedagogia, v. 13, n. 25, Jul./Set. 2019, pp. 16-26.

SANTOS, Alexandra Lima; JESUS, Evanildes Santos de. Influência das concepções de Friedrich Froebel nas atuais propostas pedagógicas. 2016. Disponivel em: <https://portal.fslf.edu.br/wpcontent/uploads/2016/12/tcc13.pdf>. Acesso em: 20 jan. 2020.

SILVA, Ezequiel Theodoro da. 0 Ato de Ler. 4 ed. São Paulo: Cortez, 1987.

SOARES, Magda. Alfabetização e letramento. 5. ed. São Paulo: Contexto, 2008.

SOLÉ, Isabel. Estratégias de leitura. Tradução: Cláudia Schilling. Revisão técnica: Maria da Graça Souza Horn. 6. ed. Porto Alegre: Penso, 2014.

VILLARDI, Raquel. Ensinando a gostar de ler: formando leitores para a vida inteira. Rio de Janeiro: Qualitymark, 1997. 